\title{
Tolerância à dessecação e armazenamento de sementes de Caesalpinia echinata Lam. (pau-brasil), espécie da Mata Atlântica
}

\author{
CLAUDIO J. BARBEDO ${ }^{1,2}$, DENISE A.C. BILIA ${ }^{1}$ e RITA DE CÁSSIA L. FIGUEIREDO-RIBEIRO ${ }^{1}$
}

(recebido: 19 de dezembro de 2001; aceito: 27 de junho de 2002)

\begin{abstract}
Desiccation tolerance and storage of seeds of Caesalpinia echinata Lam. (Brazil Wood), a species from the Atlantic Forest). The exploitation of Caesalpinia echinata reduced markedly the original geographic distribution of the species. The knowledge of seed physiology, mainly desiccation tolerance and storability, could be helpful for the conservation of the species and future recovery of degraded areas of the Atlantic Forest. Desiccation study was performed in four categories of seeds selected according to colour and size (I, II, III, and IV stages), being submitted to drying at $40^{\circ} \mathrm{C}$ and $50{ }^{\circ} \mathrm{C}$ until $8 \%$ water content was reached. Freshly harvested and dried $(9.7 \%)$ seeds were stored in cold chamber $\left(7 \pm 1^{\circ} \mathrm{C}\right)$ or in natural environment $\left(22 \pm 7^{\circ} \mathrm{C}\right)$ using packages with three different levels of permeability. Results showed that seeds of $C$. echinata are tolerant to desiccation (until $7.6 \%$ wet basis) and seed sensitivity to drying is dependent on the initial quality of the seed. Seeds stored in natural environment lost their viability in three months while under low temperatures germination was $80 \%$ after 18 months.
\end{abstract}

RESUMO - (Tolerância à dessecação e armazenamento de sementes de Caesalpinia echinata Lam. (pau-brasil), espécie da Mata Atlântica). A exploração descontrolada do pau-brasil reduziu sua distribuição original a pequenos remanescentes na atualidade. O conhecimento da fisiologia da unidade de dispersão da espécie pode contribuir para a ampliação de seu cultivo, uso racional e conservação. A sensibilidade das sementes à dessecação foi avaliada em sementes recém-colhidas, separadas em quatro categorias (estádios I, II, III e IV), segundo avaliação visual de tamanho e cor. Sementes de cada estádio foram submetidas a secagem a $40^{\circ} \mathrm{C}$ e a $50^{\circ} \mathrm{C}$, até que o teor de água atingisse $8 \%$ (base úmida). A capacidade de manutenção da viabilidade das sementes durante o armazenamento foi avaliada em diferentes embalagens (permeável, semi-permeável e impermeável), em ambiente natural $\left(22 \pm 7^{\circ} \mathrm{C}\right)$ ou em câmara fria $\left(7 \pm 1^{\circ} \mathrm{C}\right)$, com sementes submetidas ou não a secagem inicial, que reduziu o teor de água para $9,7 \%$. Os resultados permitiram concluir que as sementes de C. echinata são tolerantes à dessecação, mas a sensibilidade à secagem pode ser influenciada pela qualidade inicial das sementes. Quando armazenadas sob condições normais de ambiente podem perder a viabilidade em menos de três meses. Sob temperatura baixa foi possível manter a viabilidade das sementes por até 18 meses, com germinação superior a 80\%. A espécie em estudo comporta-se como ortodoxa, tolerando dessecação até atingir 7,6\% de água, o que pode facilitar o armazenamento e ampliar o potencial de conservação, para fins de reposição das populações naturais.

Key words - Drying, longevity, orthodox seeds, viability

\section{Introdução}

A diversidade biológica vem atraindo atenção dos mais variados setores da sociedade nos últimos anos, gerando divergências de opinião. Contudo, ainda há carência de informações científicas para subsidiar planos e ações de conservação da diversidade biológica, principalmente em áreas com maior abundância e diversidade de grupos ecológicos.

Estima-se que as florestas tropicais contenham, pelo menos, $50 \%$ de todas as espécies da superfície terrestre, não obstante cubram apenas $7 \%$ da mesma. Apesar da sua importância, as espécies dessa zona ecológica estão sendo exauridas mais rapidamente do que as de qualquer outra região do planeta (Myers

\footnotetext{
1. Instituto de Botânica, Caixa Postal 4005, 01061-970 São Paulo, SP, Brasil.

2._Autor para correspondência: cbarbedo@uol.com.br
}

1997). A Mata Atlântica é um dos biomas tropicais mais ricos em espécies, com alta incidência de endemismo (Peixoto 1991/1992). Devido à alta diversidade florística, está incluído entre os cinco maiores ecossistemas do mundo, em número de espécies, sendo considerado um "hot spot" de biodiversidade. No entanto, pouco se conhece sobre o ciclo de vida de inúmeras espécies e, conseqüentemente, sua importância para a manutenção desse complexo mosaico de ecossistemas. Sua destruição para fins diversos, ainda verificada nos dias atuais, precisa ser revertida para que a diversidade possa ser conservada (Joly et al. 1999).

A exploração descontrolada de Caesalpinia echinata Lam. (Leguminosae - Caesalpinioideae), conhecida popularmente como pau-brasil, é um dos clássicos exemplos de distúrbio causado à Mata Atlântica, iniciado logo após a ocupação da costa brasileira pelos colonizadores portugueses, reduzindo 
sua distribuição original a pequenos remanescentes na atualidade (Mello-Filho 1991/1992, Cardoso et al. 1998). Incluem-se no potencial de utilização dessa espécie, a arborização urbana e a fabricação de instrumentos musicais (Ramalho 1978, Aguiar \& Barbosa 1985, Soares 1985). A planta tem potencial ornamental (figura 1) devido à sua beleza e raridade, apresentando porte elegante, copa arredondada, folhas verde-brilhantes e flores em cacho amarelo-ouro (figuras 2-3), suavemente perfumadas (Aguiar \& Pinho 1996). Segundo Mainieri (1960), a madeira de pau-brasil é pesada, dura e apresenta cerne de coloração vermelha quando recém-cortada. Esta espécie está em perigo de extinção devido ao extrativismo exagerado e a lacunas no conhecimento referente a sua multiplicação.

Tanto para a preservação quanto para a utilização racional do pau-brasil, a produção, beneficiamento e manutenção de sementes com elevado potencial fisiológico assumem papel fundamental. Para isso, torna-se necessário o controle de alterações que ocorrem durante o armazenamento e a eventual necessidade ou sensibilidade das sementes ao processo de dessecação (Kermode 1990, Carvalho \& Nakagawa 2000), sendo importante quantificar o processo (Walters 2000). A despeito das informações existentes sobre a baixa capacidade de armazenamento das sementes de Caesalpinia echinata (Aguiar \& Barbosa 1985), situando-a como de baixa longevidade, a tecnologia de sementes tem, ainda, aspectos importantes a serem esclarecidos quanto ao armazenamento em condições apropriadas, visando a conservação da qualidade de sementes dessa espécie.

Durante o período de formação e maturação de sementes, a água assume papel crucial e seu teor permanece elevado até o final do desenvolvimento. Ao final da maturação, dois tipos de comportamento podem ser verificados: as sementes ortodoxas, que não só toleram a dessecação mas, provavelmente, dependem desse processo para redirecionar seu caminho metabólico em direção à germinação; em contraste, as sementes recalcitrantes não apenas são independentes dessa secagem para adquirir a capacidade germinativa como, ainda, apresentam limites de tolerância à dessecação. Essa diferença no comportamento das sementes pode ser considerada como resultado do processo de seleção natural, em concordância com as condições ambientais das regiões de origem da espécie (Kermode \& Bewley 1985, Kermode 1990, Barbedo \& Marcos-Filho 1998 e referências incluídas).

Respostas diferentes de sementes de espécies da família Leguminosae à desidratação já são conhecidas (Roberts 1973, Pritchard et al. 1995, Bilia et al. 1999) e o estudo da tolerância à dessecação das sementes de pau-brasil, bem como as condições ideais para o seu armazenamento, poderão permitir a ampliação do período de uso das sementes além da época em que as mesmas são produzidas, contribuindo para a conservação e preservação da espécie. O presente trabalho objetivou analisar a tolerância à dessecação dessas sementes e o seu potencial de armazenamento sob condições naturais ou controladas.

\section{Material e métodos}

As sementes de Caesalpinia echinata Lam. (figura 4) utilizadas neste trabalho foram procedentes de 200 plantas cultivadas em arboreto homogêneo, implantado em 1978 na Reserva Ecológica e Estação Experimental de Moji-Guaçu, Mogi-Guaçu, SP $\left(22^{\circ} 15^{\prime}-16^{\prime} \mathrm{S}, 47^{\circ} 8^{\prime}-12^{\prime} \mathrm{W}\right)$. Os frutos foram colhidos diretamente das árvores durante uma semana, a partir de 25/11/1999, coincidindo com o início da deiscência natural. Após a colheita, foram deixados ao sol para a liberação das sementes, as quais foram armazenadas em sacos de papel, em ambiente natural, por 10 dias. Sementes danificadas por insetos (figura 5) foram identificadas e descartadas. O material restante foi homogeneizado e separado, segundo avaliação visual de cor e tamanho, em quatro categorias, denominadas estádios I, II, III e IV. Em seguida, as sementes de cada categoria foram homogeneizadas e caracterizadas quanto ao teor de água, conteúdo de matéria seca, dimensões (maior e menor diâmetro e espessura) e germinação.

Tolerância à dessecação - Visando avaliar o nível de sensibilidade das sementes de $C$. echinata à dessecação, os materiais correspondentes a cada estádio foram submetidos a secagem em estufas com circulação forçada de ar, reguladas para $40{ }^{\circ} \mathrm{C}$ e $50{ }^{\circ} \mathrm{C}$. Para cada estádio e em ambas as temperaturas de secagem, efetuou-se o controle de perda de peso procurando-se reduzir o teor de água das sementes até $8 \%$, valor considerado adequado para armazenamento de sementes ortodoxas (Carneiro \& Aguiar 1993, Carvalho 1994, Carvalho \& Nakagawa 2000). Dessa forma, além da amostra testemunha (nível inicial de água), obtiveram-se, para cada temperatura, três níveis de secagem, denominados nível 1, nível 2 e nível 3. Após atingir cada nível de secagem estabelecido, foram avaliados o teor de água, o conteúdo de matéria seca e a germinação, através do registro do número de sementes que apresentaram raiz primária e das que resultaram em plântulas normais. $\mathrm{O}$ teor de água e o conteúdo de matéria seca foram avaliados pelo método da estufa a $105 \pm 3{ }^{\circ} \mathrm{C}$ por 24 horas (Brasil 1992), utilizando-se quatro repetições de 10 sementes cada. A germinação das sementes foi avaliada através de teste conduzido em gerbox, sobre papel (Brasil 1992), utilizando-se quatro repetições de 16 
sementes cada, em germinadores (Biomatic tipo 4001) regulados para $25^{\circ} \mathrm{C}$, com luz do ambiente de laboratório. A avaliação da germinação foi realizada 10 dias após a instalação do teste, sendo registrados o número de sementes que apresentaram raiz primária com, no mínimo, $1 \mathrm{~cm}$ (figura 6) e o número de plântulas com sistema radicular desenvolvido e o primeiro par de folhas visível (figura 7). Esses dados foram utilizados, respectivamente, para o cálculo da capacidade germinativa e da de produzir plântulas normais.

$\mathrm{O}$ delineamento experimental empregado foi o inteiramente casualizado, constituindo-se um esquema fatorial $4 \times 2 \times 4$ (estádio $\times$ temperatura de secagem $\times$ nível de secagem). Os resultados foram submetidos à análise de variância $(F, 0,05)$ e as médias foram comparadas pelo teste de Tukey, a 5\% de probabilidade.

Armazenamento de sementes - Amostras de sementes do estádio III (em maior proporção no lote original) foram divididas em duas partes, sendo uma delas submetida à secagem prévia em estufa, a $40{ }^{\circ} \mathrm{C}$, até atingir, aproximadamente, 9,5\% de água. A seguir, as sementes dos dois sublotes, "com secagem prévia" e "sem secagem prévia" (controle), foram armazenadas em dois ambientes distintos e em três tipos de embalagens: armazenamento em ambiente natural de laboratório $\left(22 \pm 7^{\circ} \mathrm{C}\right)$ e em câmara fria $\left(7 \pm 1^{\circ} \mathrm{C}\right)$, ambos em embalagem permeável (sacos de papel Kraft), semi-permeável (sacos de cloreto de polivinila - PVC, de 0,4 mm, com 10 furos de $1 \mathrm{~mm}$ de diâmetro e com a extremidade apenas dobrada) e impermeável (frascos de vidro
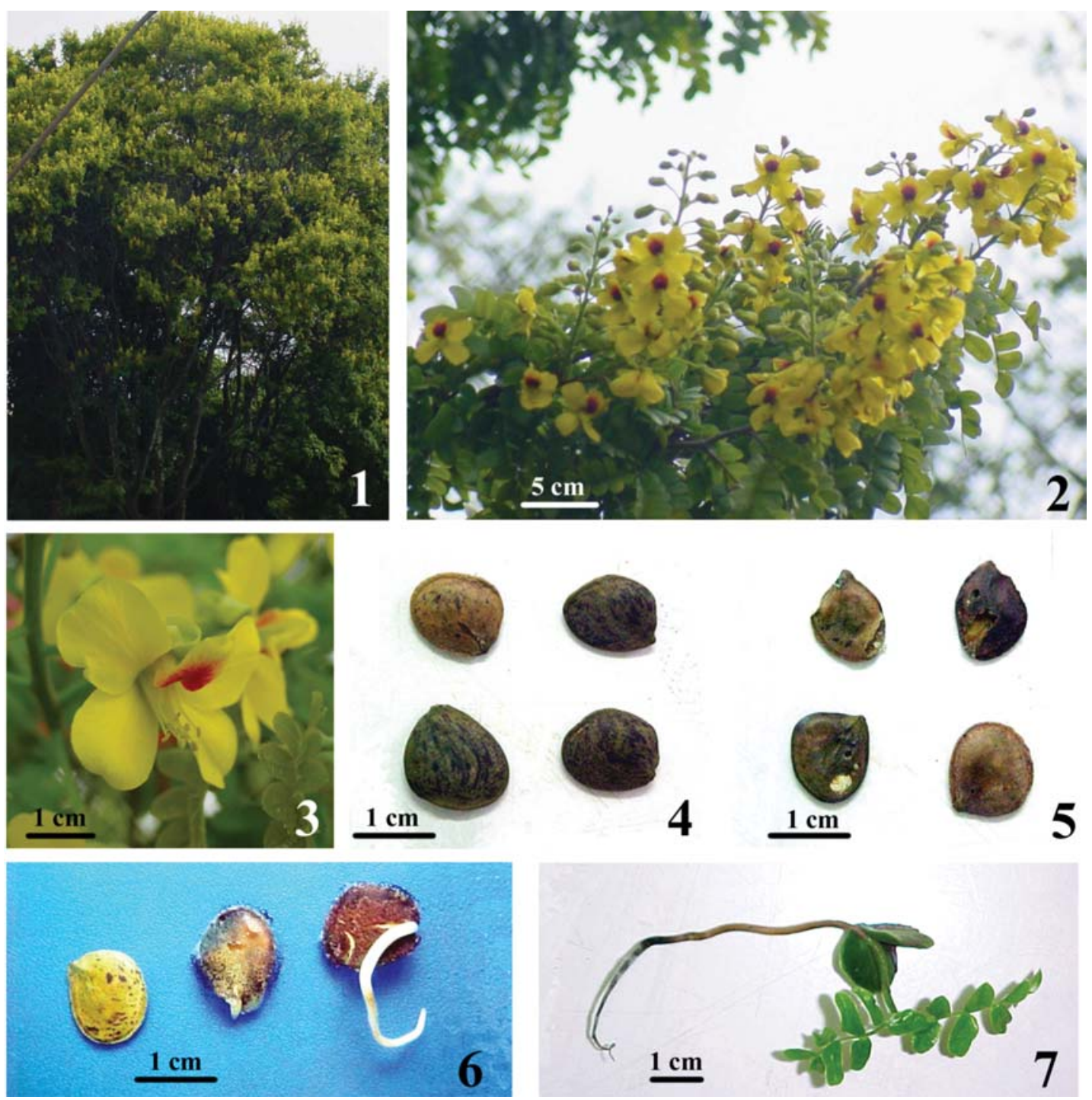

Figuras 1-7. Aspectos gerais de Caesalpinia echinata. 1. aspecto geral da árvore; 2. inflorescências; 3. detalhe da flor; 4. sementes maduras; 5. sementes maduras atacadas por insetos; 6 . fases iniciais da germinação da semente; 7. plântula normal. Fotografias originais cedidas pelo Dr. Edison Paulo Chu (Instituto de Botânica, SP). 
hermeticamente fechados com tampa de metal).

Além da avaliação inicial, foram realizadas mais quatro avaliações do potencial fisiológico das sementes durante o armazenamento, aos três, seis, 12 e 18 meses. Os parâmetros avaliados foram os mesmos descritos anteriormente.

O delineamento experimental foi o inteiramente casualizado, constituindo-se um fatorial $2 \times 2 \times 3$ (tratamento prévio $\times$ ambiente $\times$ embalagem), com quatro repetições. Os resultados foram submetidos à análise de variância $(\mathrm{F}, 0,05)$ e as médias foram comparadas entre si pelo teste de Tukey, a $5 \%$ de probabilidade.

\section{Resultados e Discussão}

A separação visual em quatro estádios foi baseada no tamanho e na coloração das sementes. As sementes do estádio I apresentavam coloração pardo-clara, levemente esverdeada, e tinham espessura de aproximadamente $0,2 \mathrm{~cm}$. As representantes do estádio II apresentavam coloração pardo-escura e espessura de aproximadamente $0,25 \mathrm{~cm}$, semelhante à das sementes dos estádios III e IV (figura 8). Estas possuíam maior uniformidade de espessura (figura 8) e diferenciaram-se pela coloração, pardo-escura uniforme no estádio III e com tons púrpura no estádio IV.

A separação dos quatro estádios resultou em diferenças mensuráveis no teor de água, no conteúdo de matéria seca e na germinação das sementes, conforme

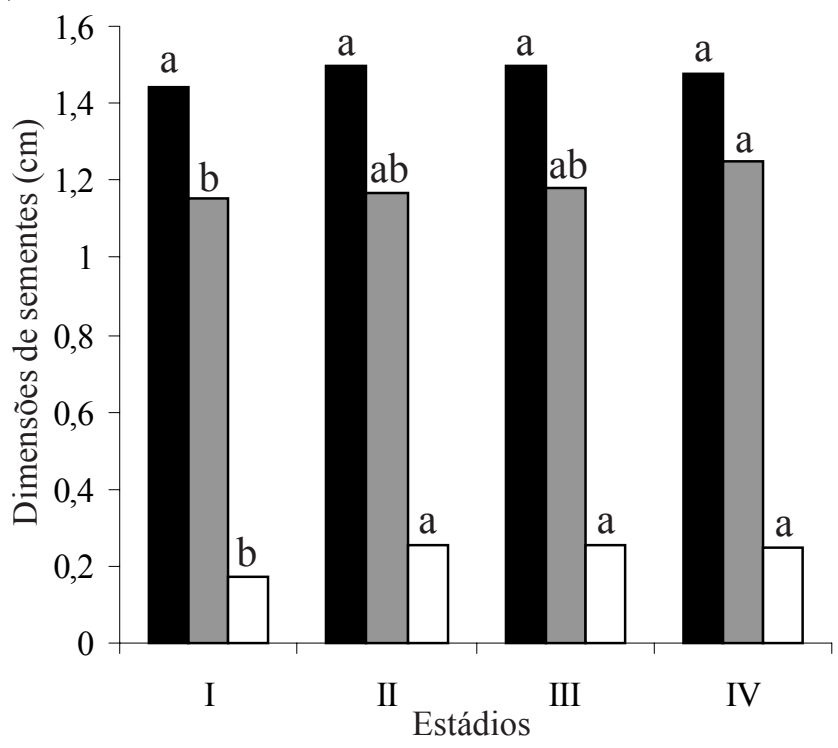

Figura 8. Dimensões de sementes de Caesalpinia echinata para cada categoria (estádios I a IV). Colunas pretas: maior diâmetro; colunas cinzas: menor diâmetro; colunas vazias: espessura. Letras iguais não diferem entre si pelo teste de Tukey, $5 \%$. pode ser observado na tabela 1 e na figura 9. Com base nessas características, estabeleceu-se que o estádio I correspondia a sementes ainda imaturas, com tamanho e conteúdo de matéria seca menores e valores inferiores de germinação. As sementes do estádio II, embora apresentando valores superiores às do I, continham matéria seca inferior às dos estádios III e IV, o que pode indicar um estádio intermediário de maturação. As sementes dos estádios III e IV, a despeito da diferença na coloração externa e no conteúdo de água, não apresentaram diferenças quanto à matéria seca, dimensões e porcentagem de germinação. Entretanto, o número de plântulas normais desenvolvidas a partir de sementes do estádio III foi significativamente superior ao estádio IV, indicando que o estádio III correspondia a sementes fisiologicamente maduras (figura 9). A identificação do estádio de maturidade fisiológica das sementes e, conseqüentemente, o momento ideal para a colheita são condições essenciais para a conservação da viabilidade durante o armazenamento (Barbedo \& Cicero 2000).

Tolerância à dessecação - Através do acompanhamento da secagem das sementes de Caesalpinia echinata do lote original, nas primeiras 10 horas, verificou-se que a perda de água para a secagem realizada a $50{ }^{\circ} \mathrm{C}$ foi mais rápida, permitindo que as sementes atingissem teor de água inferior a $8 \%$ após três horas de tratamento. Por outro lado, a $40{ }^{\circ} \mathrm{C}$ as sementes também apresentaram sensível diminuição na velocidade de perda de água, após as primeiras três horas, além de apresentarem maior resistência à redução desse teor para valores inferiores a $8 \%$ (figura 10 ).

O teor final de água em cada nível de secagem não foi influenciado pela temperatura de secagem (tabela 1). Além disso, não se observaram diferenças marcantes entre os estádios, dentro de cada nível de secagem. Esses resultados eram desejáveis, com vistas à padronização do valor final a ser atingido em cada tratamento. Assim, os teores iniciais de água, variando de $12,4 \%$ a $13,8 \%$, conforme o estádio, foram reduzidos para valores entre 9,1\%-9,9\% no primeiro nível de secagem, 8,0\%-8,9\% no segundo e 7,6\%-7,9\% no terceiro (tabela 1 ), com pequenas variações entre os diferentes estádios. As maiores diferenças foram encontradas entre os estádios I e IV, no primeiro e no segundo nível de secagem, ou seja, $0,8 \%$ e $0,9 \%$, respectivamente. Durante a secagem, o conteúdo de matéria seca das sementes praticamente não foi alterado (tabela 1 ).

A análise estatística indicou que a variação na temperatura de secagem, entre $40{ }^{\circ} \mathrm{C}$ e $50{ }^{\circ} \mathrm{C}$, não apresentou interação significativa entre este e os demais 
Tabela 1. Teor de água (\%) e conteúdo de matéria seca $\left(\mathrm{g}\right.$.semente $\left.{ }^{-1}\right)$ de sementes de Caesalpinia echinata, de quatro categorias (estádios I a IV), inicial e após três níveis (períodos) de secagem a $40{ }^{\circ} \mathrm{C} / 50^{\circ} \mathrm{C}$. C.V. $(\%)=$ coeficiente de variação.

\begin{tabular}{|c|c|c|c|c|c|}
\hline \multirow[t]{2}{*}{ Estádios } & \multicolumn{4}{|c|}{ Nível de secagem } & \multirow[t]{2}{*}{ Médias } \\
\hline & Inicial & 1 & 2 & 3 & \\
\hline & \multicolumn{4}{|c|}{ Teor de água } & \\
\hline Estádio I & $13,7 \mathrm{aA}^{1}$ & $9,1 \mathrm{bB}$ & $8,0 \mathrm{bC}$ & $7,6 \mathrm{aC}$ & 9,6 \\
\hline Estádio II & $12,4 \mathrm{bA}$ & $9,2 \mathrm{bB}$ & $8,1 \mathrm{bC}$ & $7,8 \mathrm{aC}$ & 9,4 \\
\hline Estádio III & $12,4 \mathrm{bA}$ & $9,4 \mathrm{bB}$ & $8,3 \mathrm{bC}$ & $7,8 \mathrm{aC}$ & 9,5 \\
\hline Estádio IV & 13,8 aA & $9,9 \mathrm{aB}$ & $8,9 \mathrm{aC}$ & $7,9 \mathrm{aD}$ & 10,1 \\
\hline Médias & 13,1 & 9,4 & 8,3 & 7,8 & \\
\hline \multirow[t]{2}{*}{ C.V. $(\%)$} & \multicolumn{4}{|c|}{3,60} & \\
\hline & \multicolumn{4}{|c|}{ Conteúdo de matéria seca } & \\
\hline Estádio I & $0,150 \mathrm{cA}$ & $0,160 \mathrm{cA}$ & $0,163 \mathrm{cA}$ & $0,148 \mathrm{dA}$ & 0,155 \\
\hline Estádio II & $0,224 \mathrm{bA}$ & $0,225 \mathrm{bA}$ & $0,231 \mathrm{bA}$ & $0,213 \mathrm{cA}$ & 0,223 \\
\hline Estádio III & $0,280 \mathrm{aA}$ & $0,265 \mathrm{aAB}$ & $0,271 \mathrm{aAB}$ & $0,247 \mathrm{bB}$ & 0,266 \\
\hline Estádio IV & $0,262 \mathrm{aA}$ & $0,280 \mathrm{aA}$ & $0,266 \mathrm{aA}$ & $0,273 \mathrm{aA}$ & 0,270 \\
\hline Médias & 0,229 & 0,232 & 0,233 & 0,220 & \\
\hline C.V. (\%) & & & & & \\
\hline
\end{tabular}

1 Médias seguidas pela mesma letra não diferem entre si pelo teste de Tukey, a 5\%; minúsculas comparam as colunas, maiúsculas as linhas.

fatores, nem efeito isolado sobre a germinação. Em todos os estádios analisados, as sementes de Caesalpinia echinata mostraram capacidade de suportar a secagem, germinando mesmo quando o teor de água

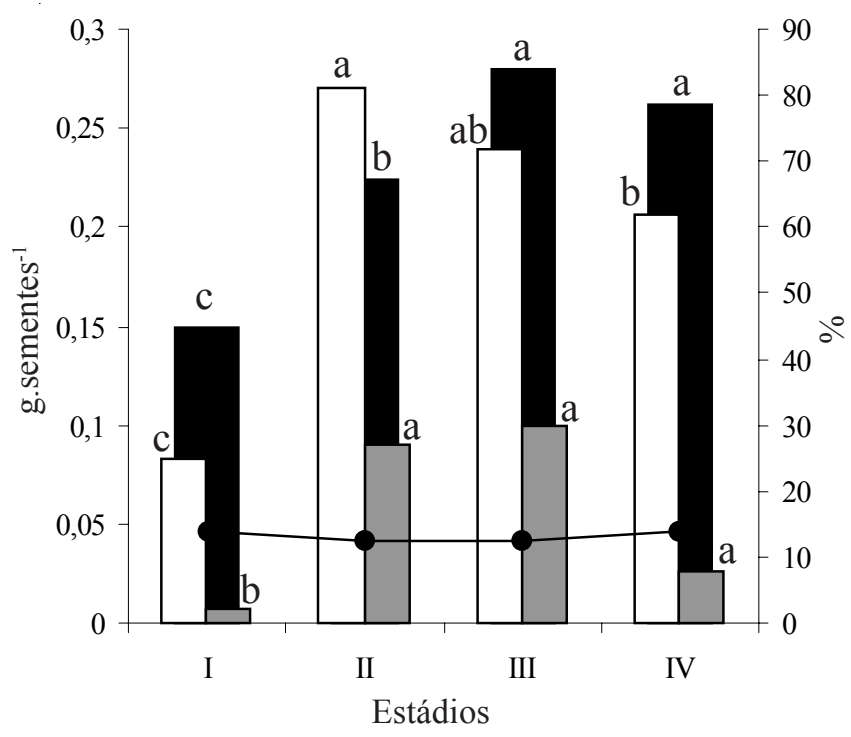

Figura 9. Teor de água (\%, linha contínua), conteúdo de matéria seca (g.semente ${ }^{-1}$, colunas pretas) e germinação (\% de sementes que originaram raiz primária, colunas vazias; $\%$ de sementes que originaram plântulas normais, colunas cinzas) de sementes de Caesalpinia echinata de diferentes categorias (estádios I a IV). Letras iguais não diferem entre si pelo teste de Tukey, $5 \%$. foi reduzido para $7,6 \%$ a 7,9\% (tabelas 1 e 2), o que corresponde ao comportamento de sementes ortodoxas (Roberts 1973). C. echinata é espécie de floresta úmida e, neste bioma, estima-se que cerca de $70 \%$ das espécies produzem sementes com comportamento recalcitrante ou intermediário. Entre estas, incluem-se Inga uruguensis (ingá), Theobroma cacao (cacau), Hevea brasiliensis (seringueira), Bertolletia excelsa (castanhado-Pará), Euterpe edulis (palmiteiro) e Paullinia cupana (guaraná) - (Andrade \& Pereira 1997, Barbedo \& Bilia 1998, Berjak \& Pammenter 2000).

É importante salientar que, apesar da redução significativa na capacidade de produzir plântulas normais (tabela 2), quando o teor de água foi reduzido para valores inferiores a $9 \%$ (tabela 1 ), a capacidade germinativa praticamente não foi afetada até o nível 2 de secagem, principalmente para as sementes do estádio IV. Além disso, para o estádio I, o nível 1 de secagem chegou a promover aumento numérico nos valores de germinação, comportamento característico de sementes ortodoxas imaturas (Carvalho \& Nakagawa 2000).

A diferença observada na tolerância à dessecação das sementes dos estádios III e IV (tabela 2) sugere que apresentem diferenças iniciais de vigor, embora não detectáveis nas avaliações iniciais realizadas, relativas a dimensões, conteúdo de matéria seca e germinação. Tal diferença poderia indicar, também, diferença no estádio de maturação entre elas. A capacidade de sementes ortodoxas resistirem à dessecação durante a 


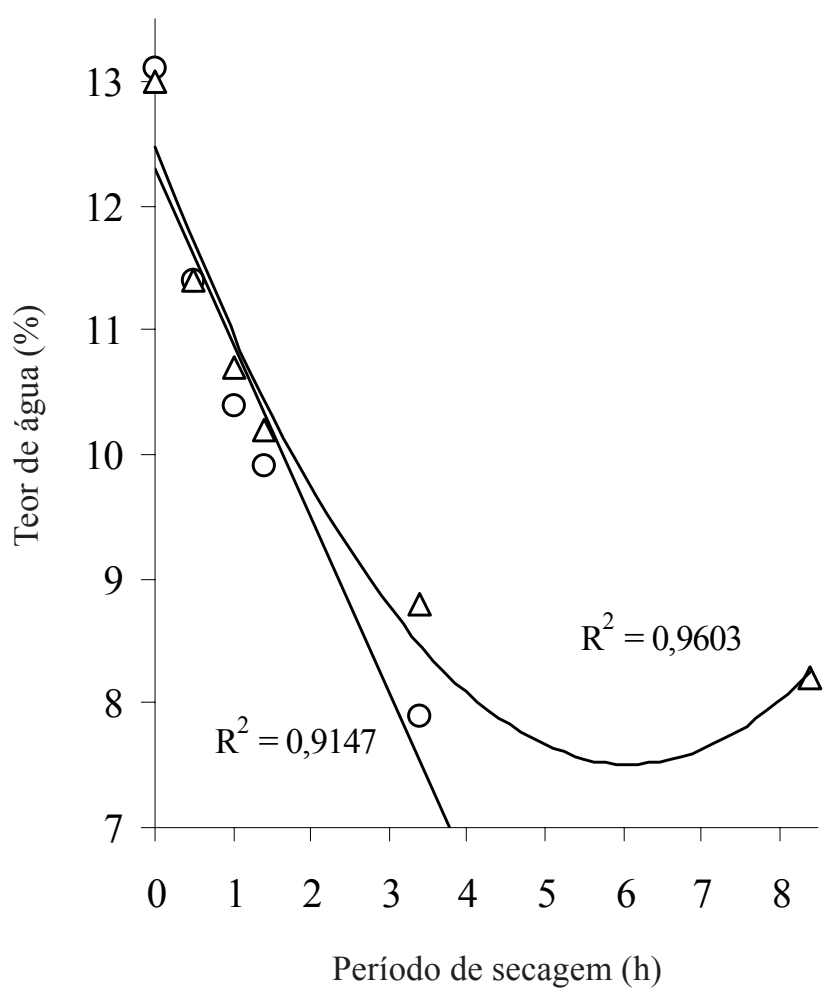

Figura 10. Teor de água (\%, em base úmida) de sementes de Caesalpinia echinata submetidas a secagem a $40^{\circ} \mathrm{C}(\Delta)$ e a $50{ }^{\circ} \mathrm{C}(\mathrm{O})$, por períodos de até 8 horas. fase de maturação geralmente é adquirida durante a fase de acúmulo de reservas, estando diretamente associada à taxa de dessecação (Pammenter \& Berjak 2000).

Armazenamento de sementes - O teor de água das sementes durante o armazenamento não apresentou modificações expressivas. De modo geral, as sementes armazenadas em câmara fria apresentaram teor de água entre $8,0 \%$ e $10,0 \%$, enquanto nas armazenadas em ambiente natural de laboratório, os valores oscilaram entre $11,5 \%$ e $12,5 \%$.

Nas tabelas 3, 4, 5 e 6 são apresentados os resultados de germinação relativos aos tratamentos cujos efeitos e interações foram significativos.

Após três meses de armazenamento em câmara fria $\left(7 \pm 1{ }^{\circ} \mathrm{C}\right)$ as sementes de Caesalpinia echinata apresentaram valores elevados de germinação (tabelas 3 e 4). Por outro lado, as sementes armazenadas em ambiente natural, independentemente do tipo de embalagem utilizada ou de secagem prévia ao armazenamento, apresentaram redução acentuada na capacidade germinativa (tabela 3 ) e, praticamente, perderam a capacidade de produzir plântulas normais (tabela 4). As sementes de C. echinata não perderam a capacidade germinativa e a de desenvolver plântulas normais mesmo após seis meses de armazenamento em

Tabela 2. Germinação (\% de sementes que originaram raiz primária e que desenvolveram plântulas normais) de Caesalpinia echinata de diferentes categorias (estádios I a IV), em função do nível de secagem das sementes a $40^{\circ} \mathrm{C} / 50^{\circ} \mathrm{C} . \mathrm{C} . \mathrm{V} .(\%)=$ coeficiente de variação.

\begin{tabular}{|c|c|c|c|c|c|}
\hline \multirow[t]{2}{*}{ Estádios } & \multicolumn{4}{|c|}{ Nível de secagem } & \multirow[t]{2}{*}{ Médias } \\
\hline & Inicial & 1 & 2 & 3 & \\
\hline & \multicolumn{4}{|c|}{ Raiz primária } & \\
\hline Estádio I & $25 \mathrm{cAB}^{1}$ & $42 \mathrm{bA}$ & 38 bA & $16 \mathrm{bB}$ & 30,2 \\
\hline Estádio II & $81 \mathrm{aA}$ & $67 \mathrm{aAB}$ & $65 \mathrm{aAB}$ & $50 \mathrm{aB}$ & 61,0 \\
\hline Estádio III & $72 \mathrm{abAB}$ & $74 \mathrm{aA}$ & $65 \mathrm{aAB}$ & $55 \mathrm{aB}$ & 66,5 \\
\hline Estádio IV & $62 \mathrm{bA}$ & $76 \mathrm{aA}$ & $73 \mathrm{aA}$ & $60 \mathrm{aA}$ & 67,8 \\
\hline Médias & 60,0 & 64,86 & 60,2 & 45,2 & \\
\hline \multirow[t]{2}{*}{ C.V. $(\%)$} & \multicolumn{4}{|c|}{17,02} & \\
\hline & \multicolumn{4}{|c|}{ Plântulas normais } & \\
\hline Estádio I & 2 & 3 & 7 & 0 & $3,0 \mathrm{~b}$ \\
\hline Estádio II & 27 & 22 & 16 & 9 & $18,5 \mathrm{a}$ \\
\hline Estádio III & 30 & 29 & 17 & 7 & $15,8 \mathrm{a}$ \\
\hline Estádio IV & 8 & 24 & 22 & 9 & $15,8 \mathrm{a}$ \\
\hline Médias & $16,8 \mathrm{~A}$ & $19,5 \mathrm{~A}$ & $15,5 \mathrm{~A}$ & $6,2 \mathrm{~B}$ & \\
\hline C.V. $(\%)$ & & & & & \\
\hline
\end{tabular}

1 Médias seguidas pela mesma letra não diferem entre si pelo teste de Tukey, a 5\%; minúsculas comparam as colunas, maiúsculas as linhas. 
Tabela 3. Germinação (\% de sementes que originaram raiz primária) de Caesalpinia echinata, submetidas ou não à secagem artificial, após três e seis meses de armazenamento em câmara fria $\left(7 \pm 1^{\circ} \mathrm{C}\right)$ e ambiente natural $\left(22 \pm 7^{\circ} \mathrm{C}\right)$ e em três tipos de embalagem (permeável, semi-permeável ou impermeável). C.V. $(\%)=$ coeficiente de variação.

\begin{tabular}{|c|c|c|c|c|}
\hline \multirow{3}{*}{$\begin{array}{c}\text { Embalagem }^{2} \\
\text { Ambiente }\end{array}$} & \multicolumn{4}{|c|}{ Período de armazenamento } \\
\hline & \multicolumn{2}{|c|}{3 meses } & \multicolumn{2}{|c|}{6 meses } \\
\hline & $\mathrm{CS}^{1}$ & SS & $\mathrm{CS}$ & SS \\
\hline Permeável & $32 \mathrm{bB}^{3}$ & $45 \mathrm{aA}$ & $42 \mathrm{abA}$ & $44 \mathrm{aA}$ \\
\hline Semi-permeável & $36 \mathrm{bA}$ & $35 \mathrm{aA}$ & $38 \mathrm{bA}$ & $43 \mathrm{aA}$ \\
\hline Impermeável & $53 \mathrm{aA}$ & $40 \mathrm{aA}$ & $47 \mathrm{aA}$ & $36 \mathrm{aB}$ \\
\hline Natural & \multicolumn{2}{|c|}{$6,4 \mathrm{~b}$} & \multicolumn{2}{|c|}{$1,0 \mathrm{~b}$} \\
\hline Câmara fria & \multicolumn{2}{|c|}{$73,7 \mathrm{a}$} & \multirow{2}{*}{\multicolumn{2}{|c|}{$\begin{array}{l}82,7 \mathrm{a} \\
22,83\end{array}$}} \\
\hline C.V. $(\%)$ & \multicolumn{2}{|c|}{29,95} & & \\
\hline
\end{tabular}

${ }^{1} \mathrm{CS}$ : com secagem prévia, SS: sem secagem prévia; ${ }^{2}$ tipo de embalagem utilizada para o armazenamento. ${ }^{3}$ Médias seguidas pela mesma letra não diferem entre si pelo teste de Tukey, a 5\%; minúsculas comparam as colunas, maiúsculas as linhas.

câmara fria, principalmente quando acondicionadas em embalagens permeável ou semi-permeável (tabelas 3 e 4). Os resultados obtidos indicam que os principais efeitos sobre a capacidade de conservação do potencial fisiológico das sementes de Caesalpinia echinata foram ocasionados pelo ambiente, neste caso pela redução da temperatura.

O armazenamento de sementes sob baixas temperaturas é benéfico para muitas espécies, algumas vezes essencial, mas é prejudicial a outras (King \& Roberts 1982, Chin et al. 1989, Andrade \& Pereira 1997, Normah et al. 1997, Sunilkumar \& Sudhakara 1998, Bilia et al. 1999). A espécie em estudo tolera o armazenamento sob baixa temperatura, que sabidamente reduz o metabolismo de sementes e de muitos microrganismos que ocorrem durante o armazenamento; isto pode ter contribuído para a manutenção da viabilidade das sementes de Caesalpinia echinata por períodos prolongados (até 18 meses de armazenamento).

Os efeitos da embalagem e da secagem prévia ao armazenamento, embora existentes, pouco contribuíram para alterar os valores iniciais (tabelas 3 e 4 ). Contudo, após 12 e 18 meses de armazenamento os efeitos desses dois fatores começaram a interferir significativamente sobre a germinação das sementes, conforme pode ser observado nas tabelas 5 e 6 .

Aos 12 meses de armazenamento (tabela 5), a germinação das sementes armazenadas em ambiente natural foi nula, independentemente dos demais fatores (embalagem e secagem prévia). Para as sementes armazenadas em câmara fria obtiveram-se diferentes comportamentos em relação às embalagens e à realização ou não de secagem prévia ao armazenamento. Assim, quando houve secagem prévia, a embalagem impermeável mostrou-se mais adequada para manter a capacidade germinativa das sementes em níveis semelhantes aos iniciais (tabela 2), mas prejudicou a capacidade das mesmas de originarem plântulas normais. Ao contrário, o armazenamento em embalagem permeável, a despeito da evidente redução na capacidade germinativa das sementes, resultou em maior número de plântulas normais que o armazenamento em embalagem impermeável.

Em relação às sementes não submetidas à secagem, a embalagem permeável mostrou-se a mais adequada para o armazenamento das sementes de Caesalpinia echinata (tabela 5).

A secagem prévia e o tipo de embalagem também interferiram nos resultados de germinação aos 18 meses de armazenamento (tabela 6). Assim, quando submetidas à secagem, as sementes não modificaram seu comportamento nas diferentes embalagens, enquanto que, quando não submetidas à secagem prévia,

Tabela 4. Germinação (\% de sementes que originaram plântulas normais) de Caesalpinia echinata, a partir de sementes submetidas ou não à secagem artificial, após três e seis meses de armazenamento em câmara fria $\left(7 \pm 1^{\circ} \mathrm{C}\right)$ e ambiente natural $\left(22 \pm 7^{\circ} \mathrm{C}\right)$ e em três tipos de embalagem (permeável, semi-permeável ou impermeável). C.V. $(\%)=$ coeficiente de variação.

\begin{tabular}{|c|c|c|c|c|c|}
\hline \multirow[t]{3}{*}{ Ambiente } & \multicolumn{5}{|c|}{ Armazenamento } \\
\hline & \multicolumn{2}{|c|}{3 meses $^{1}$} & \multicolumn{3}{|c|}{6 meses $^{2}$} \\
\hline & $\mathrm{CS}$ & SS & Permeável & Semi-permeável & Impermeável \\
\hline Natural & $1 \mathrm{bA}^{3}$ & $0 \mathrm{bA}$ & $0 \mathrm{bA}$ & $0 \mathrm{bA}$ & $0 \mathrm{bA}$ \\
\hline Câmara fria & $22 \mathrm{aB}$ & 34 aA & $37 \mathrm{aA}$ & $22 \mathrm{aAB}$ & 14 a B \\
\hline C.V.(\%) & \multicolumn{2}{|c|}{44,96} & & 65,56 & \\
\hline
\end{tabular}

${ }^{1}$ Interação significativa apenas para secagem x ambiente. CS: com secagem prévia, SS: sem secagem prévia. ${ }^{2}$ Interação significativa apenas para embalagem $\mathrm{x}$ ambiente; ${ }^{3}$ minúsculas nas colunas, maiúsculas nas linhas; Tukey, a $5 \%$. 
Tabela 5. Germinação (\% de sementes que originaram raiz primária e que desenvolveram plântulas normais) de Caesalpinia echinata, submetidas ou não à secagem prévia, após 12 meses de armazenamento em câmara fria $\left(7 \pm 1^{\circ} \mathrm{C}\right)$ e ambiente natural $\left(22 \pm 7^{\circ} \mathrm{C}\right)$ e em três tipos de embalagem. C.V. $(\%)=$ coeficiente de variação.

\begin{tabular}{|c|c|c|c|c|}
\hline \multirow[t]{2}{*}{ Embalagem } & \multicolumn{2}{|c|}{ Com secagem prévia } & \multicolumn{2}{|c|}{ Sem secagem prévia } \\
\hline & Ambiente natural & Câmara fria & Ambiente natural & Câmara fria \\
\hline \multicolumn{5}{|c|}{ Raiz primária } \\
\hline Permeável $^{1}$ & 0 a B $a^{2}$ & $77 \mathrm{ab} \mathrm{A} b$ & 0 a $\mathrm{B} a$ & 94 a A $a$ \\
\hline Semi-permeável & 0 a B $a$ & $75 \mathrm{~b}$ A $a$ & 0 a B $a$ & $75 \mathrm{~b} \mathrm{~A} a$ \\
\hline Impermeável & 0 a B $a$ & 90 a A $a$ & 0 a B $a$ & $60 \mathrm{~b} \mathrm{~A} b$ \\
\hline C.V. $(\%)$ & & 28,78 & & \\
\hline & & Plântulas normais & & \\
\hline Permeável & 0 a B $a$ & $10 \mathrm{ab} \mathrm{A} a$ & 0 a B $a$ & 17 a A $a$ \\
\hline Semi-permeável & 0 a B $a$ & 21 a A $a$ & 0 a A $a$ & $4 \mathrm{~b} \mathrm{~A} b$ \\
\hline $\begin{array}{l}\text { Impermeável } \\
\text { C.V. }(\%)\end{array}$ & 0 a A $a$ & $\begin{array}{c}4 \text { b A } a \\
74,68\end{array}$ & 0 a A $a$ & $0 \mathrm{~b} \mathrm{~A} a$ \\
\hline
\end{tabular}

${ }^{1}$ Tipo de embalagem utilizada para o armazenamento; ${ }^{2}$ letras minúsculas comparam colunas; maiúsculas, linhas entre ambientes, dentro de cada secagem; itálicas, linhas entre secagens, dentro de cada ambiente; Tukey, a 5\%.

mantiveram elevada capacidade germinativa quando acondicionadas em embalagem permeável, praticamente não germinando quando armazenada em embalagem impermeável.

Após 18 meses de armazenamento, 81\% das sementes acondicionadas em embalagem permeável e mantidas em câmara fria mantiveram a capacidade germinativa e $19 \%$ delas a capacidade de desenvolver plântulas normais (tabela 6). Estes resultados demonstram que, contrariamente à descrição existente na literatura sobre a baixa longevidade de sementes de Caesalpinia echinata (Aguiar \& Barbosa 1985), estas podem ser armazenadas por, no mínimo, 18 meses com boa conservação da sua viabilidade. Contudo, deve-se salientar a importância da qualidade inicial do lote e do emprego de embalagens permeáveis para que se obtenha tal conservação.

Finalmente, as sementes da espécie em estudo comportam-se como ortodoxas, tolerando a dessecação até baixo conteúdo de água $(7,6 \%)$, o que pode facilitar ainda mais seu armazenamento e ampliar sua conservação para fins de reposição das populações naturais, dizimadas pelo histórico extrativismo observado desde os tempos da colonização do Brasil.

Agradecimentos - Agradecemos à Fapesp pelo apoio financeiro ao projeto (Proc. 2000/06422-4) e ao CNPq pelas bolsas de produtividade em pesquisa concedidas a C.J. Barbedo e R.C.L. Figueiredo-Ribeiro. Agradecemos, também, ao Dr. Edison Paulo Chu pelas fotografias de C. echinata e aos funcionários da Reserva Biológica e Estação Experimental de Moji-Guaçu (SP) pelo fornecimento das sementes.

Tabela 6. Germinação (\% de sementes que originaram raiz primária e que desenvolveram plântulas normais) de Caesalpinia echinata, submetidas ou não à secagem prévia, após 18 meses de armazenamento em câmara fria $\left(7 \pm 1^{\circ} \mathrm{C}\right)$ e em ambiente natural $\left(22 \pm 7^{\circ} \mathrm{C}\right)$ e em três tipos de embalagem. C.V. $(\%)=$ coeficiente de variação.

\begin{tabular}{|c|c|c|c|c|c|c|}
\hline \multirow[t]{3}{*}{ Embalagem } & \multicolumn{4}{|c|}{ Raiz primária (\%) } & \multirow{2}{*}{\multicolumn{2}{|c|}{$\begin{array}{c}\text { Plântulas normais } \\
\qquad(\%)\end{array}$}} \\
\hline & \multicolumn{2}{|c|}{ Com secagem } & \multicolumn{2}{|c|}{ Sem secagem } & & \\
\hline & $\mathrm{AN}^{1}$ & $\mathrm{CF}$ & AN & $\mathrm{CF}$ & AN & $\mathrm{CF}$ \\
\hline Permeável & 0 a B $a^{2}$ & 79 a A $a$ & 0 a B $a$ & 81 a A $a$ & $0 \mathrm{aB}$ & $19 \mathrm{aA}$ \\
\hline Semi-permeável & 0 a B $a$ & 79 а А $a$ & 0 a B $a$ & $54 \mathrm{~b}$ A $b$ & $0 \mathrm{aA}$ & $2 \mathrm{bA}$ \\
\hline Impermeável & 0 a B $a$ & 73 a A $a$ & 0 a A $a$ & $6 \mathrm{c} \mathrm{A} b$ & $0 \mathrm{aA}$ & $0 \mathrm{bA}$ \\
\hline C.V. $(\%)$ & \multicolumn{4}{|c|}{32.71} & \multicolumn{2}{|c|}{74,68} \\
\hline
\end{tabular}

${ }^{1} \mathrm{AN}$ : ambiente natural, CF: câmara fria; ${ }^{2}$ médias seguidas pela mesma letra não diferem entre si pelo teste de Tukey, a 5\%; minúsculas comparam as colunas, maiúsculas as linhas, itálicas as secagens. 


\section{Referências bibliográficas}

AGUIAR, F.F.A. \& BARBOSA, J.M. 1985. Estudo de conservação e longevidade de sementes de pau-brasil (Caesalpinia echinata Lam.). Ecossistema 10:145-50.

AGUIAR, F.F.A. \& PINHO, R.A.1996. Pau-brasil: Caesalpinia echinata Lam. 2a ed. Instituto de Botânica, São Paulo. Folheto 18.

ANDRADE, A.C.S. \& PEREIRA, T.S. 1997. Comportamento de armazenamento de sementes de palmiteiro (Euterpe edulis Mart.). Pesquisa Agropecuária Brasileira 32: 987-991.

BARBEDO, C.J. \& BILIA, D.A.C. 1998. Evolution of research on recalcitrant seeds. Scientia Agricola 55 (ed. especial): 121-125.

BARBEDO, C.J. \& CICERO, S.M. 2000. Effects of initial quality, low temperature and ABA on the storage of seeds of Inga uruguensis, a tropical species with recalcitrant seeds. Seed Science and Technology 28:793-808.

BARBEDO, C.J. \& MARCOS-FILHO, J. 1998. Tolerância à dessecação de sementes. Acta Botanica Brasilica 12:145-164.

BERJAK， P. \& PAMMENTER, N. 2000. What ultraestructure has told us about recalcitrant seeds. Revista Brasileira de Fisiologia Vegetal 12 (Edição especial):22-55.

BILIA, D.A.C., MARCOS-FILHO, J. \& NOVEMBRE, A.D.C.L. 1999. Desiccation tolerance and seed storability of Inga uruguensis (Hook. et Arn.). Seed Science and Technology 27:77-89.

BRASIL, 1992. Ministério da Agricultura e Reforma Agrária. Regras para análise de sementes. Brasília.

CARDOSO, M.A., PROVAN, J., POWELL,W., FERREIRA, P.C.G. \& DE OLIVEIRA, D.E. 1998. High genetic differentiation among remnant populations of the endangered Caesalpinia echinata Lam. (Leguminosae - Caesalpinoideae). Molecular Ecology 7: 601-608

CARNEIRO, J.G.A. \& AGUIAR, I.B. 1993. Armazenamento de sementes. In Sementes florestais tropicais (I.B. Aguiar, F.C.M. Piña-Rodrigues \& M.B. Figliolia, eds.). Abrates, Brasília. p.333-350.

CARVALHO, N.M. 1994. A secagem de sementes. Funep, Jaboticabal.

CARVALHO, N.M. \& NAKAGAWA, J. 2000. Sementes: ciência, tecnologia e produção. 4a ed. Funep, Jaboticabal.

CHIN, H.F., KRISHNAPILLAY, B. \& STANWOOD, P.C. 1989. Seed moisture: recalcitrant vs. orthodox seeds. In Seed moisture (P.C. Stanwood \& M.B. McDonald, eds.). Crop Science Society of America, Madison. p.15-22.

JOLY, C.A., AIDAR, M.P.M., KLINK, C.A., MCGRATH, D.G., MOREIRA, A.G., MOUTINHO, P., NEPSTAD, D.C., OLIVEIRA, A.A., POTT, A., RODAL, M.J.N. \& SAMPAIO, E.V.S.B. 1999. Evolution of the Brazilian phytogeography classification systems: implications for biodiversity conservation. Ciência e Cultura 51:331-348.
KERMODE, A.R. 1990. Regulatory mechanisms involved in the transition from seed development to germination. Critical Reviews in Plant Sciences 9:155-195.

KERMODE, A.R. \& BEWLEY, J.D. 1985. The role of maturation drying in the transition from seed development to germination. II. Acquisition of desiccation-tolerance and germinability during development of Ricinus communis L. seeds. Journal of Experimental Botany 36:1906-1915.

KING, M.W. \& ROBERTS, E.H. 1982. The imbibed storage of cocoa (Theobroma cacao) seeds. Seed Science and Technology 10:535-540.

MAINIERI, C. 1960. Estudo macro e microscópico de madeiras conhecidas por pau-brasil. IPT, São Paulo. Publicação 612.

MELLO-FILHO, L.E. 1991/1992. A Floresta Atlântica. In Floresta Atlântica/textos científicos. (S. Monteiro \& L. Kaz, coord.). Edições Alumbramento, Rio de Janeiro. p.17-21.

MYERS, N. 1997. Florestas tropicais e suas espécies. Sumindo, sumindo...? In Biodiversidade (E.O.Wilson, ed.). Nova Fronteira, Rio de Janeiro. p.36-45.

NORMAH, M.N., RAMIYA, S.D. \& GINTANGGA, M. 1997. Desiccation sensitivity of recalcitrant seeds - a study on tropical fruit species. Seed Science Research 7:179-183.

PAMMENTER, N. \& BERJAK, P. 2000. Aspects of recalcitrant seed physiology. Revista Brasileira de Fisiologia Vegetal 12 (Edição especial):56-69.

PEIXOTO, A.L. 1991/1992. A vegetação da Costa Atlântica. In Floresta Atlântica - textos científicos (S. Monteiro \& L. Kaz, coord.). Edições Alumbramento, Rio de Janeiro. p.33-42

PRITCHARD, H.W., HAYE, A.J., WRIGHT, W.J. \& STEADMAN, K.J. 1995. A comparative study of seed viability in Inga species: desiccation tolerance in relation to the physical characteristics and chemical composition of the embryo. Seed Science and Technology 23:77-89.

RAMALHO, R.S. 1978. Pau-brasil (Caesalpinia echinata Lam.). Universidade Federal de Viçosa, Viçosa. Boletim de Extensão 12. p.1-11.

ROBERTS, E.H. 1973. Predicting the storage life of seeds. Seed Science and Technology 1:499-514.

SOARES, C.M.C. 1985. Pau-brasil: a árvore nacional. $2^{2}$ ed. Universidade Federal Rural de Pernambuco/Estação Ecológica do Tapacurá, Recife.

SUNILKUMAR, K.K. \& SUDHAKARA, K. 1998. Effect of temperature, media and fungicide on the storage behaviour of Hopea parviflora seeds. Seed Science and Technology 26:781-797.

WALTERS, C. 2000. Levels of recalcitrance in seeds. Revista Brasileira de Fisiologia Vegetal 12 (Edição especial):7-21. 